\title{
Prevention of venipuncture pain in children: a comparative study of topical anesthetics
}

Prevenção da dor na punção venosa em crianças: estudo comparativo entre anestésicos tópicos Prevención del dolor en la punción venosa en niños: estudio comparativo entre anestésicos tópicos

Luís Manuel da Cunha Batalha*(D); Maria Matilde Marques Correia**

\begin{abstract}
Background: The ideal topical anesthetic to prevent venipuncture pain should have high efficacy, a quick effect, a good safety profile, be easy to apply, low cost, and well accepted.

Objective: To compare the effectiveness of 5 topical anesthetics in children who require venipuncture.

Methodology: A randomized controlled study was conducted involving 350 children (6 - 17 years) who were randomly allocated to 5 groups. Pain was assessed using the Visual Analog Scale $(0$ to $10 \mathrm{~cm})$. Between-group differences were analyzed using the Chi-square test and the Kruskal-Wallis test and within-group differences were analyzed using the Wilcoxon test.

Results: All anesthetics were effective in preventing pain (mean pain intensity $\leq 1.1$ ) and no between-group differences were found $(p>0.05)$. Ease of venous access, vein visibility and/or palpability, successful cannulation, and the child's cooperation were good and similar between groups $(p>0.05)$.

Conclusion: The differences between topical anesthetics were only significant in the procedures required for their application and the costs, for which reason the use of ethyl chloride should be reconsidered.
\end{abstract}

Keywords: child; pain; anesthetics; nursing

\section{Resumo}

Enquadramento: $\mathrm{O}$ anestésico tópico ideal para prevenir a dor por punçáo deveria possuir alta eficácia, efeito rápido, bom perfil de segurança, fácil aplicação, baixo custo e boa aceitação.

Objetivo: Comparar a efetividade de 5 anestésicos tópicos em crianças que necessitam de uma punção venosa. Metodologia: Estudo randomizado controlado envolvendo 350 crianças (6 - 17 anos) com alocaçáo randomizada em 5 grupos. A dor foi avaliada através da Escala Visual Analógica (0 a $10 \mathrm{~cm}$ ). As diferenças entre os grupos foram analisadas pelos testes do Qui-quadrado e Kruskal-Wallis e, nos grupos, pelo teste Wilcoxon.

Resultados: Todos os anestésicos revelaram eficácia na prevenção da dor (intensidade média de dor $\leq 1,1$ ) e sem diferenças entre os grupos $(p>0,05)$. A facilidade de punção, visibilidade e/ou palpação da veia, o sucesso na punção e a cooperação da criança foi boa e semelhante entre os grupos $(p>0,05)$.

Conclusáo: As diferenças significativas entre os anestésicos tópicos apenas existiram nos procedimentos requeridos na sua aplicação e custos, pelo que se deve repensar o uso do cloreto de etilo.

Palavras-chave: criança; dor; anestésicos; enfermagem

*Ph.D., Professor, Nursing School of Coimbra, Health Sciences Research Unit: Nursing, 3046-851, Coimbra, Portugal [batalha@esenfc.pt].(1) http://orcid.org/00000002-5328-1470. Contribution to the article: Literature review, methodological design of the studv and elaboration of the data collection tools, data interpretation and analvsis, article writing, revision of versions, and final approval. Address for correspondence: Avenida Bissaya Barreto - Ap. 7001, 3046-851, Coimbra, Portugal.

**MSc., Specialist Nurse, Coimbra Hospital and University Center, EPE, 3000-076, Coimbra, Portugal [matildecorreia@gmail.com]. Contribution to the article: Elaboration of the data collection tools, data collection, critical content revision, and final approval.

Revista de Enfermagem Referência

\section{Resumen}

Marco contextual: El anestésico tópico ideal para prevenir el dolor por punción debería poseer alta eficacia, efecto rápido, buen perfil de seguridad, fácil aplicación, bajo coste y buena aceptación.

Objetivo: Comparar la efectividad de 5 anestésicos tópicos en nińos que necesitan una punción venosa.

Metodología: Estudio aleatorio controlado que involucró a 350 niños (de 6 a 17 años) a los cuales se los distribuyó de forma aleatoria en 5 grupos. El dolor se evaluó a través de la Escala Visual Analógica (de 0 a 10 $\mathrm{cm}$ ). Las diferencias entre los grupos se analizaron por las pruebas de Chi cuadrado y Kruskal-Wallis y, en los grupos, por la prueba Wilcoxon.

Resultados: Todos los anestésicos revelaron eficacia en la prevención del dolor (intensidad media del dolor $\leq$ $1,1)$ y $\sin$ diferencias entre los grupos $(p>0,05)$. La facilidad de punción, visibilidad y/o palpación de la vena, el éxito en la punción y la cooperación del niño fueron buenas y similares entre los grupos $(p>0,05)$.

Conclusión: Solo existieron diferencias significativas entre los anestésicos tópicos en los procedimientos requeridos en su aplicación y costes, por lo que se debe repensar el uso del cloruro de etilo.

Palabras clave: niño; dolor; anestésicos; enfermería

Received for publication: 10.04 .18

Accepted for publication: 05.07 .18

Série IV - n. ${ }^{0} 18$ - JUL./AGO./SET. 2018 


\section{Introduction}

Venipuncture (VP) is a routine nursing procedure which is often performed in children and has the potential to produce pain, anxiety, fear, and distress if preventive measures are not taken (Bice, Gunther, \& Wyatt, 2014; Waterhouse, Liu, \& Wang, 2013; Zempsky, 2008). Many children still fear needle puncture procedures (Dalvandi, Ranjbar, Hatamizadeh, Rahgoi, \& Bernstein, 2017), which is why more than $10 \%$ of adults report being afraid of needles (Schechter et al., 2007).

There is a wide variety of effective pharmacological and non-pharmacological options for preventing needle-related procedural pain. In children, distraction and hypnosis, when carefully selected and implemented, are effective in preventing this type of pain (Uman et al., 2013), as well as sucrose in newborn infants (Stevens, Yamada, Ohlsson, Haliburton, \& Shorkey, 2016). With regard to pharmacological interventions, there is a wide variety of options administered by topical or inhalation routes (Zempsky, 2008). However, the waiting period to establish full analgesic effect is a significant barrier to their use, which has stimulated the development of new topical anesthetics and the revival of old ones, such as ethyl chloride. This anesthetic stopped being used after the development of new, safer drugs because of its possible adverse effects, but the controversy remains as to the use of ethyl chloride in clinical practice (Bond et al., 2016; Fossum, Love, \& April, 2016; Hogan, Smart, Shah, \& Taddio, 2014; Zempsky, 2008).

This study aimed to compare the effectiveness of five topical anesthetics for preventing VP pain in children in an outpatient department of a pediatric hospital. Effectiveness covers analgesic efficacy, safety (no adverse effects), clinical utility (ease of venous access, good vein visibility and/or palpability, number of attempts until successful cannulation, and child's cooperation), and costs.

\section{Background}

The ideal topical anesthetic to prevent venipuncture pain should have high efficacy, a quick and enduring effect, a good safety pro- file, be easy to apply, low cost, and be well accepted by children, parents, and health professionals (Zempsky, 2008).

There are many available options, which proves that none of them has all the ideal characteristics. Zempsky (2008) describes several topical anesthetics for preventing venous access pain. The anesthetic effect of lidocaine $10 \%$ spray usually occurs within 1 to 3 minutes and remains for about 10 to 15 minutes. The anesthetic effect of lignocaine hydrochloride $2 \%$ gel starts after 5 minutes and lasts approximately 20 to 30 minutes. EMLA $^{\circledR}$ cream is a mixture of $2.5 \%$ lidocaine and $2.5 \%$ prilocaine, being one of the first commercially available topical anesthetics to be applied to intact skin. Analgesia occurs within 60-90 minutes and it requires an occlusive dressing. Lidocaine $4 \%$ cream requires 30 minutes for full analgesic effect, but it also requires an occlusive dressing. Among other options available, ethyl chloride has a reasonable cost, is easy to apply, and has an immediate effect, which offers advantages for use in outpatient departments (Soueid \& Richard, 2007). It was first used in 1955 as an anesthetic (Davies \& Molloy, 2006) and stopped being used as other relatively safer anesthetics became available. It functions by rapidly cooling the skin, slowing initiation and conduction of impulses in cutaneous sensory nerves (Zempsky, 2008). Vapocoolant sprays consist of volatile liquid refrigerants applied on intact skin immediately before cannulation. Their rapid evaporation produces a short analgesic effect (less than 1 minute). Their use is safe (Farion, Splinter, Newhook, Gaboury, \& Splinter, 2008; Fossum et al., 2016; Griffith, Jordan, Herd, Reed, \& Dalziel, 2016) and their side effects include rare allergic reactions and minor temporary skin changes. If its application exceeds 10 seconds (minimum time to cause skin blanching), it leads to skin cooling with potential damage of local cells (Farion et al., 2008); however, possible injuries are avoided if applications do not exceed 30 seconds (Davies \& Molloy, 2006). Rare cases can be associated with allergic contact dermatitis and prolonged spraying can cause hypopigmentation and atrophic scarring, especially in people with poor circulation. Most vapocoolant sprays contain chemicals that are eye irritants, so eye contact should be avoided.

The evidence on the analgesic efficacy of ethyl 
chloride is inconsistent (Farion et al., 2008; Griffith et al., 2016; Waterhouse et al., 2013), partly as a result of the use of different methodological procedures which confound comparisons. Studies use different protocols for the application of ethyl chloride (application time and distance to the skin), assess pain using different scales and follow-up moments, and make comparisons using multiple variables and products, as well as very different sample sizes.

In a recent systematic review comparing the use of ethyl chloride vapocoolant spray with placebo or no treatment in 1,070 children and adults, the authors found moderate-quality evidence indicating that use of ethyl chloride vapocoolant spray immediately before VP reduced pain in approximately $1.25 \mathrm{~cm}$ in the Visual Analog Scale (VAS), did not increase the difficulty of cannulation, and caused no serious adverse effects, despite being associated with mild discomfort during application (Griffith et al., 2016).

In a randomized controlled study comparing the efficacy of ethyl chloride vapocoolant spray with a placebo in 80 children aged 6 to 12 years, statistically significant differences were found: reduction in VAS pain scores when using ethyl chloride $(5.6 \pm 3.19$ vs $3.6 \pm$ 2.75), successful cannulation on first attempt, and improved satisfaction among children, parents, and nurses (Farion et al., 2008).

In a cross-over experimental study with 77 children aged 5 to 13 years undergoing three VP with a 2-hour interval, the authors compared the efficacy of ethyl chloride spray with tetracaine cream. In the first and second VP, ethyl chloride was compared to tetracaine in terms of efficacy. In the third VP, the anesthetic method used was the one chosen by the child (ethyl chloride or tetracaine). Pain was assessed using the Wong-Baker Faces Scale, and the results revealed equal efficacy for both anesthetics, but with an advantage to ethyl chloride ( $1^{\text {st }} V P: 0.84$ vs $0.97 ; 2^{\text {nd }} V P: 1.05$ vs $1.13 ; 3^{\text {rd }} \mathrm{VP}: 0.48$ vs 0.91$)$ and a greater preference to ethyl chloride in children $(56 \%$; Davies \& Molloy, 2006).

In a study conducted with 129 children aged 9 to 18 years which compared the effect of ethyl vinyl chloride vapocoolant spray with a placebo spray and no spray, similar results were found in all groups. Mean VAS scores for children's self-reported pain were 3.4, 3.3, and $3.1 \mathrm{~cm}$, respectively (Costello, Ramundo, Christopher, \& Powell, 2006).

Ethyl chloride has advantages when compared to other topical anesthetics, namely its quick action, easy application, lack of a waiting time, and reduced costs. However, doubts remain as to its analgesic efficacy and clinical utility due to inconsistent results (Dalvandi et al., 2017; Griffith et al., 2016; Waterhouse et al., 2013).

\section{Research question}

What is the comparative effectiveness of five topical anesthetics for preventing VP pain in children in an outpatient department of a pediatric hospital?

\section{Methodology}

A randomized controlled study was conducted involving 350 children (162 boys and 188 girls) aged 6 to 17 years, with a median of 11 years. These children used the outpatient department of a pediatric hospital, accompanied by their parents, and had to undergo a VP. The following exclusion criteria were applied: children with a history of atopic dermatitis or any other skin barrier dysfunction; children unable to assess pain intensity using VAS or answer the question about their degree of fear.

This study was approved by the Board of Directors and Ethics Committee of the hospital where the study was developed and followed the recommendations of the World Medical Association Declaration of Helsinki. Before the children's participation, the children's legal guardian(s) had to sign an informed consent form.

A total of 15 nurses working at the department participated in data collection, after explanation and clarification of doubts about the study protocol. All of them received training on how to apply the topical anesthetics and assess pain intensity using VAS (Reed \& Van Nostran, 2014).

Participants were randomly allocated into 
five groups using the GraphPad Software Inc. Sample size was calculated using a clinically significant difference of $1.5 \mathrm{~cm}$ in VAS, assuming an $80 \%$ power to detect differences at a significance level of $5 \%$ and a standard deviation of $3 \mathrm{~cm}$ (Farion et al., 2008). At least 68 observations would be required per group, thus sample size was extended to 70 observations per group.

The intervention consisted in the application of five topical anesthetics used in the outpatient department for preventing VP pain during blood sampling using a 23G butterfly needle on the dorsum of the hand or antecubital fossa. Anesthetics were applied following the recommendations used at the hospital department. Groups were distributed as follows: Group 1 (lidocaine 10\% spray) spraying three times at cannulation site from a distance of approximately $5 \mathrm{~cm}$, followed by cleaning of the surrounding area using a gauze pad and leaving it to act for 5 minutes; Group 2 (lignocaine hydrochloride 2\% gel) application of a thick layer followed by slight massage until the area is demarcated, leaving it to act for five minutes; Group 3 (lidocaine and prilocaine EMLA $^{\Theta}$ cream, 2.5\%/2.5\%) - application of a thick layer of cream covered with plastic film, leaving it to act for 60 minutes; Group 4 (ethyl chloride spray) spraying the cannulation site from a distance of about $10 \mathrm{~cm}$ for about 5 seconds or until the skin blanched (whichever occurred first), followed by cleaning with a gauze pad and immediate cannulation; and Group 5 (lidocaine $4 \%$ cream) - application of thick layer covered with plastic film, leaving it to act for 30 minutes.

Before cannulation, children's demographic and clinical data were collected and vein visibility and/or palpability was assessed, as well as children's perception of fear and pain intensity. Immediately after cannulation, ease of venous access, the number of attempts un- til successful cannulation, the child's cooperation during the procedure, pain intensity, and the possible adverse effects of anesthetics were assessed.

The questionnaire for demographic and clinical characterization included a self-report question where children answered if they were afraid or not afraid. The nurses assessed ease of venous access, vein visibility and/or palpability, and the child's cooperation during the procedure as bad or good.

Pain intensity was assessed using the self-report measure VAS, which measures pain from $0 \mathrm{~cm}$ (no pain) to $10 \mathrm{~cm}$ (maximum pain; Bailey, Gravel, \& Daoust, 2012).

Data were analyzed using the statistical software IBM SPSS Statistics, version 23. Kolmogorov-Smirnov test and histogram were used to test for a normal distribution and showed that none of the variables met the assumption of normality. Absolute and relative frequencies were used for categorical variables and the median and the interquartile range were used for continuous variables. In some cases, to facilitate data interpretation, maximum and minimum limits, mean, and standard deviation were calculated. For categorical variables, between-group differences were analyzed using the Chi-square test. For continuous variables, the Kruskal-Wallis test one-way ANOVA was used for independent samples (between-groups) and the Wilcoxon test was used for paired samples (within-groups, before and after the VP). In all tests, statistical significance was set at $p<0.05$.

\section{Results}

The five groups showed no differences in the sociodemographic and clinical variables, with the exception of age. The highest median age (13 years) was found in Group 4 and the lowest in groups 3 and 5 (10 years; Table 1$)$. 
Table 1

Children's demographic and clinical variables

\begin{tabular}{lcccccc}
\hline & \multicolumn{5}{c}{ Groups } & \multirow{2}{*}{$p$} \\
\cline { 2 - 6 } & 1 & 2 & 3 & 4 & 5 & $<0.001$ \\
\hline Age, med. (IQR) & $11.5(6)$ & $12.0(6)$ & $10.0(4)$ & $13.0(4)$ & $10.0(4)$ & NS \\
Male gender, $n(\%)$ & $38(54.3)$ & $36(51.4)$ & $25(35.7)$ & $33(47.1)$ & $30(42.9)$ & NS \\
With chronic disease, $n(\%)$ & $29(41.4)$ & $32(45.7)$ & $38(54.3)$ & $36(51.4)$ & $32(45.7)$ & NS \\
Previous experience of VP, $n(\%)$ & $64(91.4)$ & $66(94.3)$ & $67(95.7)$ & $68(97.1)$ & $64(91.4)$ & NS \\
Afraid, $n(\%)$ & $39(55.7)$ & $28(40.0)$ & $43(61.4)$ & $30(42.9)$ & $36(51.4)$ & N
\end{tabular}

Note. $\mathrm{VP}=$ venipuncture; med. = median; $\mathrm{IQR}=$ interquartile range; NS = non-significant

Vein visibility/palpability, ease of venous access, and the child's cooperation were similar between groups. However, in Group 4 (ethyl chloride), nurses reported that more children had good vein visibility/palpability (60;85.7\%). In Group 5 (lidocaine $4 \%$ cream), cannulation was easier (63 cases; 90.0\%) and children were less cooperative (57; 81.4\%). The number of attempts until successful cannulation was similar, first attempt (median of 1). In Group 5 (lidocaine 4\% cream), cannulation was always successful on first attempt (1-1), as can be seen in Table 2.

Table 2

\section{Clinical utility of the topical anesthetics}

\begin{tabular}{lcccccc}
\hline & \multicolumn{5}{c}{ Groups } & \\
\cline { 2 - 5 } & 1 & 2 & 3 & 4 & 5 & \\
\hline Good vein visibility/palpability, $n(\%)$ & $58(82.9)$ & $58(82.9)$ & $54(77.1)$ & $60(85.7)$ & $57(81.4)$ & NS \\
Easy cannulation, $n(\%)$ & $61(87.1)$ & $59(84.3)$ & $60(85.7)$ & $62(88.6)$ & $63(90.0)$ & NS \\
$\begin{array}{l}\text { Attempts until successful cannulation, } \\
\text { med. (min.- max.) }\end{array}$ & $1(1-3)$ & $1(1-3)$ & $1(1-3)$ & $1(1-2)$ & $1(1-1)$ & - \\
Good child's cooperation, $n(\%)$ & $64(91.4)$ & $64(91.4)$ & $60(85.7)$ & $64(91.4)$ & $57(81.4)$ & NS \\
\hline
\end{tabular}

Note . med. = median; $\min .=$ minimum $; \max .=$ maximum; $\mathrm{NS}=$ non-significant .

All topical anesthetics showed statistically significant differences between children's selfreported pain before and after cannulation in each group $(p<0.001)$ and, between them, none of them showed a statistically significant difference in pain prevention (NS). The lowest

Table 3

Pain intensity in the several groups/different topical anesthetics

\begin{tabular}{|c|c|c|c|c|c|c|}
\hline & \multicolumn{5}{|c|}{ Groups } & \multirow{2}{*}{$p$} \\
\hline & 1 & 2 & 3 & 4 & 5 & \\
\hline \multicolumn{7}{|l|}{$\begin{array}{l}\text { Pain intensity, } \\
M \pm S D ; \text { med. } \\
\text { (IQR) }\end{array}$} \\
\hline Before VP & $0.1 \pm 0.2 ; 0(0)$ & $0.1 \pm 0.7 ; 0(0)$ & $0.0 \pm 0.3 ; 0(0)$ & $0.0 \pm 0.1 ; 0(0)$ & $0.3 \pm 1.3 ; 0(0)$ & NS \\
\hline After VP & $1.0 \pm 1.6 ; 0(1)$ & $1.1 \pm 1.6 ; 0(2)$ & $0.7 \pm 1.6 ; 0(1)$ & $1.1 \pm 1.7 ; 0(2)$ & $1.1 \pm 1.7 ; 0(1)$ & NS \\
\hline$p$ & $<0.001$ & $<0.001$ & $<0.001$ & $<0.001$ & $<0.001$ & NS \\
\hline
\end{tabular}

Note. $M=$ Mean; $S D=$ standard deviation; med. = median; $\mathrm{IQR}=$ interquartile range; $\mathrm{VP}=$ venipuncture; $\mathrm{NS}=$ non-significant. mean difference in pain intensity, before and after VP, was found in Group 3 (lidocaine and prilocaine, $2.5 \% / 2.5 \% ; 0.7)$ and the highest was found in Group 4 (ethyl chloride; 1.1), as shown in Table 3.

\footnotetext{
(a)
}

LUIS MANUEL DA CUNHA BATALHA et al. 
No adverse effects of these anesthetics were reported.

\section{Discussion}

The analyzed topical anesthetics proved to have analgesic efficacy for preventing VP pain in children. Although the differences between pain intensity before and after cannulation were statistically significant, they were below the clinically accepted value of $1.5 \mathrm{~cm}$ in the VAS (Farion et al., 2008; Griffith et al., 2016; Hogan et al., 2014). After the VP, pain intensity was always less than $3 \mathrm{~cm}$, which is a good indicator for pain management (Batalha et al., 2014). In absolute terms, the EMLA $^{\circledR}$ cream (lidocaine and prilocaine, $2.5 \% / 2.5 \%$ ) proved to be the most effective anesthetic and the ethyl chloride the least effective. These results are in line with other studies (Bond et al., 2016; Dalvandi et al., 2017), despite not being consensual (Dalvandi et al., 2017).

The topical anesthetics for preventing VP pain are similar in terms of their pharmacological action, which involves inhibition of sodium ion channels in sensory neurons (Zempsky, 2008). The exception is ethyl chloride, which operates by cooling the skin. Anesthetics differ from each other mainly in how they are applied and the time required for onset of full anesthetic effect.

The sociodemographic and clinical characteristics were similar between groups, with the exception of age. This difference, although statistically significant, is not clinically significant because the anatomical and physiological characteristics of a 10-year-old are not very different from those of a 13-year-old. However, the younger the child, the greater the vulnerability to perceive pain with greater intensity (Zempsky, 2008). Curiously, the group of children who received analgesia with ethyl chloride had a higher median age than those who received EMLA ${ }^{\circledR}$ cream (lidocaine and prilocaine, $2.5 \% / 2.5 \%$ ). The lack of control for this variable poses doubts that must be analyzed in future studies, not only regarding the efficacy of the anesthetic according to age, but also regarding the possible influence of the anatomical and physiological characteristics of age on pain perception in case of a painful stimulus such as VP. Another non-controlled variable was the cannulation site: dorsum of the hand or antecubital fossa. Although we are unaware of studies exploring the differences in pain perception based on the cannulation site, this variable should have been controlled for.

In the past 30 years, topical anesthetics for preventing venous access pain have evolved towards reducing the time required for onset of full anesthetic effect and the number of adverse effects. This study found no adverse effects of anesthetics, which contradicts unfounded fears regarding the use of ethyl chloride (Kelly, 2008; Soueid \& Richard, 2007). Very different methods are used to apply ethyl chloride for preventing pain. The distance varies between 7 and 25 $\mathrm{cm}$ and the spraying time between 2 and 10 seconds (Hogan et al., 2014). The decision to spray the area from a distance of about $10 \mathrm{~cm}$ for 5 seconds or until skin blanching (whichever occurred first) was a conservative measure which followed the protocol used in most of the studies (Hogan et al., 2014) and proved to be safe. The development of a mechanism to limit the spraying time for a safe use would be very useful for this type of topical anesthetics.

There is a wide range of topical anesthetics which, despite having similar efficacy and safety, differ in the application procedures, the time required for the analgesic effect, ease of venous access, and costs. These variables should be considered in choosing the ideal anesthetic for a given clinical context.

Clinical utility depends on vein visibility/palpability, ease and success of cannulation, and the child's cooperation. In this study, anesthetics showed similarities regarding their utility, and it should be noted that nurses reported that more children had better vein visibility/palpability while using ethyl chloride, which can be explained by the immediate cannulation after its application. The lack of interference of ethyl chloride in the difficulty of cannulation and, consequently, its success were also described in other studies (Costello et al., 2006; Griffith et al., 2016; Taddio, Soin, Schuh, Koren, \& Scolnik, 2005). In children who received lidocaine $4 \%$ cream, most nurses reported that cannulation was easier and more successful. This finding was also found when comparing its use with a placebo (Taddio et al., 2005).

For health institutions' managers, the cost-ben- 
efit of drugs is an important variable for choosing them. Taking into account over-the-counter prices, the cost per application of the most expensive anesthetic - EMLA ${ }^{\circledR}$ cream (lidocaine and prilocaine, $2.5 \% / 2.5 \%$ ) - is 2.5 times higher than that of the least expensive anesthetic - ethyl chloride. In the department where the study was conducted, there are on average 25 samples taken per day, thus the estimated 6,375 samples would represent direct savings of 2,678 Euros per year if the least expensive anesthetic was used.

EMLA $^{\circledR}$ cream (lidocaine and prilocaine, $2.5 \% / 2.5 \%$ ) is the most expensive anesthetic and has a greater waiting period to establish full effect, besides requiring an occlusive dressing, like lidocaine $4 \%$ cream (Zempsky, 2008). These indirect costs must be considered in a cost-benefit analysis, as well as parents and children's time away from work and school, respectively, the costs with the application of the occlusive dressing, and the time spent by the nurse in this task.

This study had some methodological limitations: the fact that two cannulation sites were used, although we are unaware of studies showing differences in pain perception associated with the cannulation site; although the use of a placebo group (innocuous intervention) could provide more information about the effectiveness of anesthetics or the influence of other variables, such as suggestion, it would raise ethical issues in its implementation; and the lack of a double-blinding, which was impossible due to the nature of the intervention.

Some issues require further research, such as the efficacy of anesthetics based on the child's age, the cannulation site, the protocol for ethyl chloride application (different distances from the skin and spraying time), influence of suggestion and non-pharmacological techniques, such as distraction, and the possible effects of waiting times on anxiety.

\section{Conclusion}

The ideal topical anesthetic to prevent venipuncture pain should have high efficacy, a quick and enduring effect, a good safety profile, be easy to apply, low cost, and be well accepted by children, parents, and health professionals.
The analyzed topical anesthetics were effective in preventing pain, had no adverse effects, and contributed to an easy and successful cannulation. The differences related to the procedures required for their application, the waiting periods to establish full anesthetic effect, and the costs. Ethyl chloride does not require a waiting time between its application and VP, or an occlusive dressing and is considerably less expensive than the other anesthetics. These characteristics, without prejudice to the study of other pharmacological and non-pharmacological pain management interventions, support the recommendation for the use of ethyl chloride in preventing venous access pain in children. Ethyl chloride can be particularly useful in emergency or outpatient departments, where the waiting period is a barrier to the implementation of measures for preventing VP pain.

\section{References}

Bailey, B., Gravel, J., \& Daoust, R. (2012). Reliability of the visual analog scale in children with acute pain in the emergency department. Pain, 153(4), 839-842. doi:10.1016/j.pain.2012.01.006

Batalha, L., Costa, L., Reis, G., Jacinto, F., Machado, R., \& Santos, P. (2014). Dor pediátrica em Portugal: Resultados da sensibilização e formação. Acta Pediátrica Portuguesa, 45(2), 99-106. Retrieved from http://actapediatrica.spp.pt/article/view/2723/3026

Bice, A. A., Gunther, M., \& Wyatt, T. (2014). Increasing nursing treatment for pediatric procedural pain. Pain Management Nursing, 15(1), 365-379. doi:10.1016/j. pmn.2012.06.004

Bond, M., Crathorne, L., Peters, J., Coelho, H., Haasova, M., Cooper, C., ... Powell, R. (2016). First do no harm: Pain relief for the peripheral venous cannulation of adults, a systematic review and network meta-analysis. BMC Anesthesiology, 16(1), 81. doi:10.1186/ s12871-016-0252-8

Costello, M., Ramundo, M., Christopher, N. C., \& Powell, K. R. (2006). Ethyl vinyl chloride vapocoolant spray fails to decrease pain associated with intravenous cannulation in children. Clinical Pediatrics, 45(7), 628-632. doi:10.1177/0009922806291013

Dalvandi, A., Ranjbar, H., Hatamizadeh, M., Rahgoi, A., \& Bernstein, C. (2017). Comparing the effectiveness of vapocoolant spray and lidocaine/procaine cream in reducing pain of intravenous cannulation: A randomized clinical trial. The American Journal of Emer- 
gency Medicine, 35(8), 1064-1068. doi:10.1016/j. ajem.2017.02.039

Davies, E. H., \& Molloy, A. (2006). Comparison of ethyl chloride spray with topical anaesthetic in children experiencing venepuncture. Paediatric Nursing, 18(3), 39-43. doi: 10.7748/paed2006.04.18.3.39.c8136

Farion, K. J., Splinter, K. L., Newhook, K., Gaboury, I., \& Splinter, W. M. (2008). The effect of vapocoolant spray on pain due to intravenous cannulation in children: A randomized controlled trial. Canadian Medical Association Journal, 179(1), 31-36. doi:10.1503/ cmaj.070874

Fossum, K., Love, S. L., \& April, M. D. (2016). Topical ethyl chloride to reduce pain associated with venous catheterization: A randomized crossover trial. The American Journal of Emergency Medicine, 34(5), 845850. doi:10.1016/j.ajem.2016.01.039

Griffith, R. J., Jordan, V., Herd, D., Reed, P. W., \& Dalziel, S. R. (2016). Vapocoolants (cold spray) for pain treatment during intravenous cannulation. Cochrane Database of Systematic Reviews, 4, CD009484. doi:10.1002/14651858.CD009484.pub2

Hogan, M.-E., Smart, S., Shah, V., \& Taddio, A. (2014). A systematic review of vapocoolants for reducing pain from venipuncture and venous cannulation in children and adults. The Journal of Emergency Medicine, 47(6), 736-749. doi:10.1016/j.jemermed.2014.06.028

Kelly, J. (2008). Painless vascular cannulation: Ethyl chloride, vapocoolants and cryoanalgesics. The Journal of the Collegial Physicians of Edinburg, 38(3), 232-233. Retrieved from https://www.rcpe.ac.uk/sites/default/ files/kelly_1.pdf

Reed, M. D., \& Van Nostran, W. (2014). Assessing pain intensity with the visual analog scale: A plea for uniformity. The Journal of Clinical Pharmacology, 54(3),
241-244. doi:10.1002/jcph.250

Schechter, N. L., Zempsky, W. T., Cohen, L. L., McGrath, P. J., McMurtry, C. M., \& Bright, N. S. (2007). Pain reduction during pediatric immunizations: Evidence-based review and recommendations. Pediatrics, 119(5), e1184-e1198. doi:10.1542/peds.2006-1107

Soueid, A., \& Richard, B. (2007). Ethyl chloride as a cryoanalgesic in pediatrics for venipuncture. Pediatric Emergency Care, 23(6), 380-383. doi:10.1097/01. pec.0000278396.25129.3f

Stevens, B., Yamada, J., Ohlsson, A., Haliburton, S., \& Shorkey, A. (2016). Sucrose for analgesia in newborn infants undergoing painful procedures. The Cochrane Database of Systematic Reviews, 7, CD001069. doi:10.1002/14651858.CD001069.pub5

Taddio, A., Soin, H. K., Schuh, S., Koren, G., \& Scolnik, D. (2005). Liposomal lidocaine to improve procedural success rates and reduce procedural pain among children: A randomized controlled trial. Canadian Medical Association Journal, 172(13), 1691-1695. doi:10.1503/cmaj.045316

Uman, L. S., Birnie, K. A., Noel, M., Parker, J. A., Chambers, C. T., McGrath, P. J., \& Kisely, S. R. (2013). Psychological interventions for needle-related procedural pain and distress in children and adolescents. The Cochrane Database of Systematic Reviews, 10, CD005179. doi:10.1002/14651858.CD005179.pub3

Waterhouse, M. R., Liu, D. R., \& Wang, V. J. (2013). Cryotherapeutic topical analgesics for pediatric intravenous catheter placement: Ice versus vapocoolant spray. Pediatric Emergency Care, 29(1), 8-12. doi:10.1097/PEC.0b013e31827b214b

Zempsky, W. T. (2008). Pharmacologic approaches for reducing venous access pain in children. Pediatrics, 122 (sup. 3), S140-S153. doi:10.1542/peds.2008-1055g 